\title{
STRUCTURAL BARRIERS FOR HEALTH CARE PROFESSIONALS TO PROMOTE PHYSICAL ACTIVITY TO CANCER PATIENTS
}

$\underline{\text { Karen Steindorf }}^{1}$, Alexander Haussmann ${ }^{1}$, Nadine Ungar ${ }^{2}$, Martina Gabrian ${ }^{2}$

Angeliki Tsiouris $^{3}$, Monika Sieverding ${ }^{2}$, Joachim Wiskemann ${ }^{3}$

\section{Introduction}

Physical activity (PA) has been recognized as a beneficial selfmanagement strategy for cancer patients, e.g. for their quality of life [1] or even regarding mortality [2]. However, health care professionals (HCP) still do not promote PA to cancer patients routinely [3]. Several studies have tried to target influential factors that hinder $\mathrm{HCP}$ in promoting PA, but have focused on HCP' attitudes. Taking into account different professional groups and settings in health care, we assumed that also structural barriers have a substantial impact.

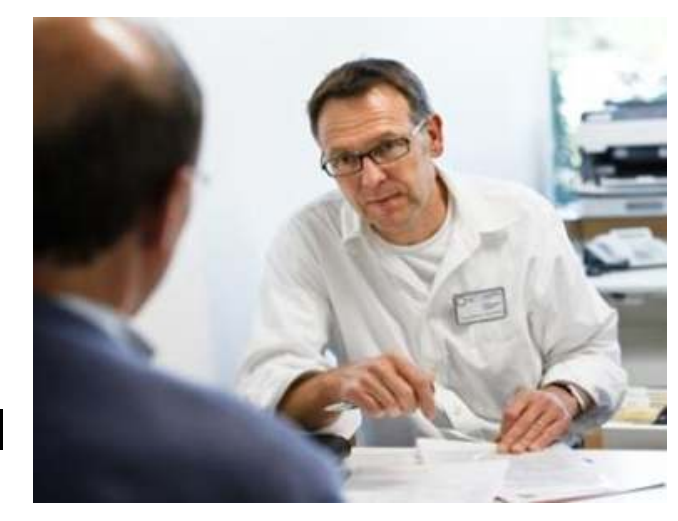

\section{Methods}

917 HCP (287 physicians working in outpatient care, 242 physicians working in inpatient care, and 388 oncology nurses) completed a comprehensive questionnaire.

9 items assessed structural barriers on a 4-point Likert Scale. They were analyzed using descriptive statistics and compared between professional groups using one-way analysis of variance and subsequent post hoc tests with Bonferroni correction. HCP' PA promotion behavior was also analyzed descriptively and was predicted by structural barriers using multiple ordinal regressions. Regressions were adjusted for sociodemographic variables and HCP' attitude.

\section{Results}

Self-reported PA promotion behavior of HCP is shown by profession in Table 1. The proportion of HCP who indicated to recommend PA towards at least $50 \%$ of their cancer patients was $88.5 \%$ among physicians working in outpatient care, $78.1 \%$ among physicians working in inpatient care, and $73.1 \%$ among oncology nurses.

Table 1. Self-reported physical activity promotion behavior of health care professionals towards cancer patients

\begin{tabular}{|l|c|c|c|}
\hline & $\begin{array}{c}\text { Physicians } \\
\text { working in } \\
\text { outpatient care }\end{array}$ & $\begin{array}{c}\text { Physicians } \\
\text { working in } \\
\text { inpatient care }\end{array}$ & $\begin{array}{c}\text { Oncology } \\
\text { nurses }\end{array}$ \\
\hline $\begin{array}{l}\text { Advised against doing physical } \\
\text { activity }\end{array}$ & 0.3 & $\%$ & $\%$ \\
\hline $\begin{array}{l}\text { Never/rarely recommended } \\
\text { physical activity } \\
\text { (<10\% of patients) }\end{array}$ & 0.7 & 0.4 & 0.3 \\
\hline $\begin{array}{l}\text { Recommended physical } \\
\text { activity sometimes } \\
\text { (10-50\% of patients) }\end{array}$ & 10.5 & 3.3 & 7.0 \\
\hline $\begin{array}{l}\text { Recommended physical } \\
\text { activity often } \\
\text { (50-90\% of patients) }\end{array}$ & 35.0 & 18.2 & 40.6 \\
\hline $\begin{array}{l}\text { Recommended physical } \\
\text { activity routinely } \\
(>90 \% \text { of patients) }\end{array}$ & 53.5 & 41.3 & 32.3 \\
\hline
\end{tabular}

Table 2 displays how HCP perceived different structural barriers as impeding for their PA promotion and how professional groups differed in this perception. Overall, highest ranked structural barriers were time per patient and a lack of structured and reimbursed therapeutic programs.
Table 2. Comparison of perceptions of structural barriers to promote physical activity to cancer patients between three groups of health care professionals

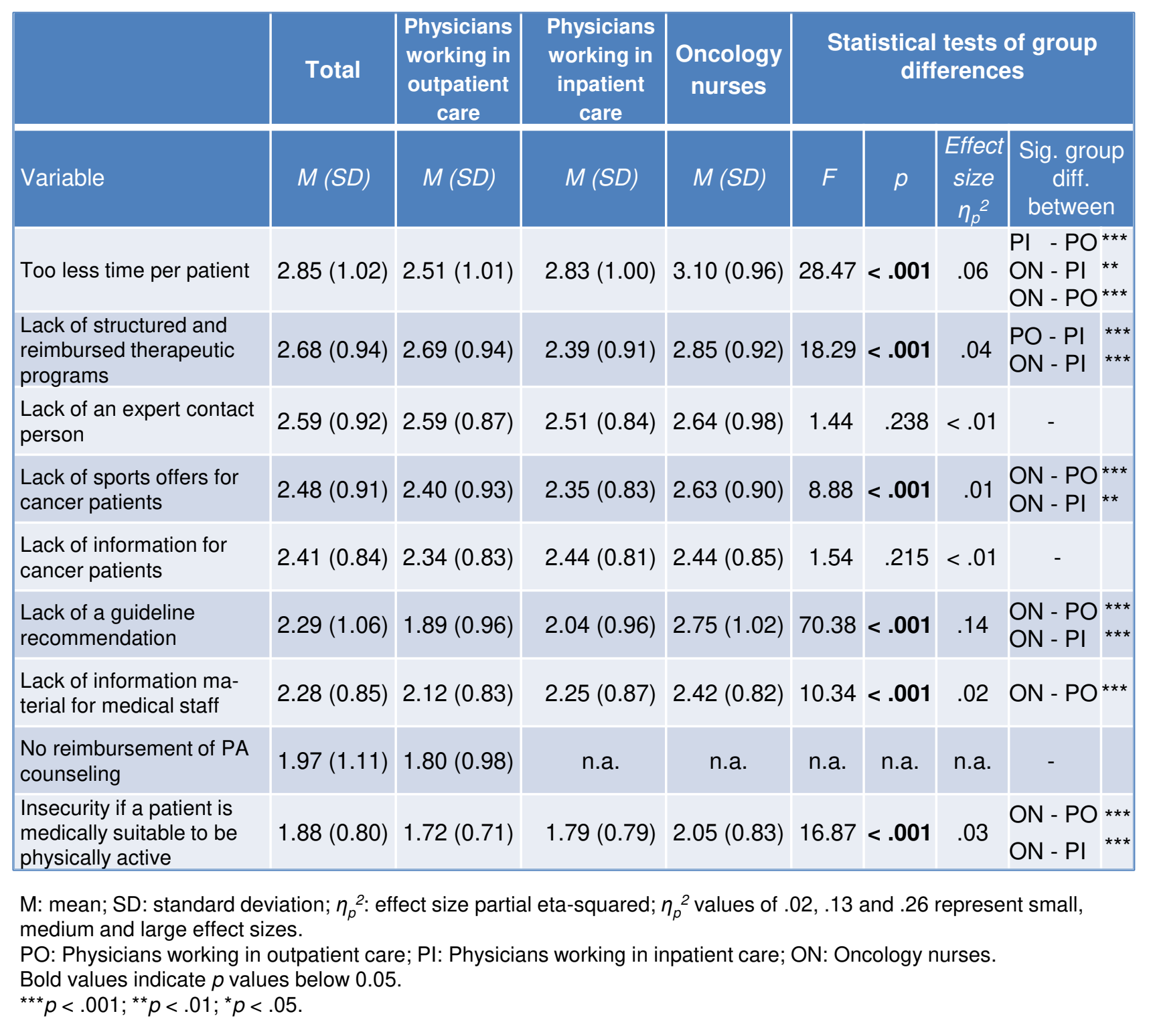

The influence of structural barriers on the PA promotion behavior varied between professional groups: perceiving too less time per patient' turned out to be a significant determinant for a reduced PA promotion among physicians working in outpatient care [OR 0.35 $(0.20,0.61), p<.001]$, and among oncology nurses [OR $0.60(0.36$, $0.99), p=.045]$. Only among physicians working in outpatient care perceiving 'lack of a guideline recommendation' as impeding was associated with a reduced PA promotion behavior [OR $0.46(0.25$, $0.84), p=.011]$. Perceiving 'lack of an expert contact person' was a determinant for a reduced PA promotion among physicians working in inpatient care [OR $0.50(0.28,0.91), p=.019]$, and oncology nurses [OR $0.58(0.35,0.96), p=.035]$.

\section{Discussion}

Results of our study suggest that the large majority of HCP nowadays promotes PA to most of their cancer patients. Their PA promotion behavior seems to be influenced by structural barriers: Lack of an expert contact person in the inpatient care and too less time per patient in the outpatient care seem to hinder HCP in promoting PA.

\section{Conclusion}

A large proportion of HCP reported to frequently promote PA. However, our findings suggest that HCP still perceive structural barriers. To further improve cancer patients' supportive care with regard to $\mathrm{PA}$, it seems important to target structural barriers specifically for different professional groups.
Acknowledgments: This study was part of the Momentum Projekt and was supported by a grant from the German Cancer Aid | Deutsche Krebshilfe.

\section{Momentum ( $\approx$ Deutsche Krebshilfe}

Publication: Haussmann A, Ungar N, Gabrian M, Tsiouris A, Sieverding M, Wiskemann J, Steindorf K (2018) Are health care professionals being left in the lurch? The role of structural barriers and information resources to promote physical activity to cancer patients. Supp Care Cancer, in press. 